\title{
PPAR-y2 and PTPRD gene polymorphisms influence type 2 diabetes patients' response to pioglitazone in China
}

Qi PEI ${ }^{1,2}$, Qiong HUANG ${ }^{3}$, Guo-ping YANG ${ }^{1,4}$, Ying-chun ZHAO ${ }^{5}$, Ji-ye $\mathrm{YIN}^{1}$, Min SONG ${ }^{4}$, Yi ZHENG ${ }^{1}$, Zhao-hui MO ${ }^{6, *}$, Hong-hao ZHOU ${ }^{1}$, Zhao-qian LIU ${ }^{1, *}$

${ }^{1}$ Institute of Clinical Pharmacology, Hunan Key Laboratory of Pharmacogenetics, Central South University, Changsha 410078, China; ${ }^{2}$ Department of Pharmacy, Third Xiangya Hospital, Central South University, Changsha 410013, China; ${ }^{3}$ Institute of Clinical Pharmacology, Anhui Medical University, Hefei 230032, China; ${ }^{4}$ Center of Clinical Pharmacology, Third Xiangya Hospital, Central South University, Changsha 410013, China; ${ }^{5}$ Osteoporosis Research Center, Creighton University, Omaha, NE 68131, USA; ${ }^{6}$ Department of Endocrinology, Third Xiangya Hospital, Central South University, Changsha 410013, China

Aim: To investigate the influence of peroxisome proliferator-activated receptor y2 (PPAR-y2) gene polymorphism rs1801282 and protein tyrosine phosphatase receptor type D (PTPRD) gene polymorphism rs17584499 on the occurrence of type 2 diabetes and pioglitazone efficacy in a Chinese Han population.

Methods: One hundred ninety seven type 2 diabetes patients and 212 healthy controls were enrolled. Among them, 67 type 2 diabetes patients were administered pioglitazone $(30 \mathrm{mg} / \mathrm{d}, \mathrm{po})$ for 3 months. All the subjects were genotyped for genetic variants in PPAR-y2 and PTPRD using MALDI-TOF mass spectrometry. Fasting plasma glucose, postprandial plasma glucose, glycated hemoglobin, serum triglyceride, total cholesterol, low-density and high-density lipoprotein-cholesterol were determined.

Results: The PPAR-y2 gene rs1801282 polymorphism was significantly associated with type 2 diabetes susceptibility (OR=0.515, 95\% $\mathrm{Cl}$ 0.268-0.990) and the PTPRD gene rs17584499 polymorphism was also significantly associated with type 2 diabetes (OR=1.984, 95\% Cl 1.135-3.469) in a dominant model adjusted for age, gender and BMI. After pioglitazone treatment for 3 months, the type 2 diabetes patients with PPAR-y2 rs1801282 CG genotypes significantly showed higher differential values of postprandial plasma glucose and serum triglyceride compared with those with rs1801282 CC genotype. The patients with PTPRD rs17584499 CT+TT genotypes showed significantly lower differential value of postprandial plasma glucose compared to those with rs $17584499 \mathrm{CC}$ genotype.

Conclusion: Diabetes risk alleles in PPAR-y2 (rs1801282) and PTPRD (rs17584499) are associated with pioglitazone therapeutic efficacy.

Keywords: pioglitazone; type 2 diabetes; PPAR-ү2 rs1801282; PTPRD rs17584499; genetic polymorphisms; Chinese Han population

Acta Pharmacologica Sinica (2013) 34: 255-261; doi: 10.1038/aps.2012.144; published online 12 Nov 2012

\section{Introduction}

Type 2 diabetes is a chronic complex metabolic disease, which is obviously influenced by genetic components and environmental factors ${ }^{[1]}$. Many studies focused on finding susceptibility gene loci for type 2 diabetes, including genome-wide linkage study, candidate gene study, and genome-wide association study (GWAS). Genome-wide linkage study showed that the peroxisome proliferators-activated receptor- $\gamma 2(\operatorname{PPAR}-\gamma 2)$ gene

\footnotetext{
* To whom correspondence should be addressed.

E-mail liuzhaoqian63@126.com (Zhao-qian LIU); easd04mzh@126.com (Zhao-hui MO)

Received 2012-07-27 Accepted 2012-09-18
}

was associated with type 2 diabetes ${ }^{[2]}$. PPAR- $\gamma 2$ belongs to the nuclear hormone receptor superfamily of ligand-dependent transcription factors ${ }^{[3]}$ and is predominantly expressed in adipose tissue ${ }^{[4]}$. It is involved in adipocyte differentiation, regulating glucose and lipid homeostasis ${ }^{[4]}$. The most common polymorphism rs1801282 (Pro12Ala) occurs in 12\% of the Finnish population ${ }^{[5]}$ and in $14 \%$ of the German population ${ }^{[6]}$. The rs1801282 is a missense mutation that causes the replacement of proline by alanine at codon 12 of PPAR- $\gamma 2$ gene ${ }^{[7]}$. This gene affected type 2 diabetes patients not only on susceptibility but also on anti-diabetic therapeutic efficacy. Patients carrying CG genotype of rs1801282 showed a better rosiglitazone therapeutic efficacy than the CC genotype subjects ${ }^{[8]}$. 
Recently, a Chinese Han GWAS reported several new genetic loci associated with type 2 diabetes ${ }^{[9]}$. Among them, protein tyrosine phosphatase receptor type D (PTPRD) gene showed the strongest association and largest odds ratio $(\mathrm{ORs})^{[9]}$. PTPRD is a member of protein tyrosine phosphatases (PTPs) receptor type IIA (R2A) subfamily ${ }^{[10]}$, which plays a significant role in diabetes ${ }^{[11]}$. The strongest associated polymorphism is rs17584499, which is located in the intron 10 of PTPRD gene ${ }^{[9]}$. Although the intronic single nucleotide polymorphisms (SNPs) is generally regarded to have no functional meaning, it may influence the splicing or the stability of $\mathrm{mRNA}^{[12-14]}$, and consequently changes the gene expression level. Additionally, the intronic SNP may be a marker of association with other functional polymorphisms.

Pioglitazone, a new insulin-sensitizing drug, belongs to thiazolidinedione (TZD), which is widely used for type 2 diabetes patients ${ }^{[15,16]}$. PPAR- $\gamma 2$ gene is a target gene for pioglitazone. The binding of PPAR- $\gamma 2$ and pioglitazone activates transcription of genes involved in glucose and lipid metabolism ${ }^{[17,18]}$. Type 2 diabetes patients treated with pioglitazone showed decrease in blood glycated hemoglobin (HbA1c) ${ }^{[17]}$, triglyceride, total cholesterol, and low-density lipoprotein-cholesterol (LDL-c) and increase in high-density lipoprotein-cholesterol $(\mathrm{HDL}-\mathrm{c})^{[19]}$. It has been reported that pioglitazone therapeutic efficacy in type 2 diabetes patients showed individual differences ${ }^{[20-23]}$.

In this study, we intend to explore the effect of PPAR- ${ }^{2}$ gene rs1801282 and PTPRD gene rs17584499 polymorphism on pioglitazone therapeutic efficacy in Chinese Han type 2 diabetes patients.

\section{Materials and methods}

\section{Subjects}

A total of 197 patients with type 2 diabetes and 212 healthy controls of Chinese Han population were recruited in the Third Xiangya Hospital, Central South University, Changsha in China. There were no significant differences with regard to age and sex between controls and cases, but a significant difference in body mass index (BMI) was found between controls and cases. Type 2 diabetes was diagnosed according to the World Health Organization criteria from 1999: fasting plasma glucose test $(\mathrm{FPG}) \geq 7.0 \mathrm{mmol} / \mathrm{L}$ or $2 \mathrm{~h}$ postprandial plasma glucose test $(\mathrm{PPG}) \geq 11.1 \mathrm{mmol} / \mathrm{L}$. We excluded patients with type 1 diabetes, ischemic heart disease, congestive heart failure, kidney or liver diseases; patients receiving insulin treatment or other drugs, which affect the glucose metabolism (such as glucocorticoids); and pregnant or lactating patients. The inclusion criteria were as follows: (1) BMI between 19 and $30 \mathrm{~kg} / \mathrm{m}^{2}$, (2) the duration of diabetes was more than three months, (3) no administration of any insulin secretagogue, agonist or inhibitor of CYP2C8, CYP3A4 in the past 3 months, (4) no TZD use, and (5) no change in medication in the last 3 months. The study protocol was approved by the Ethics Committee of Third Xiangya Hospital, Central South University and was in accordance with the Helsinki Declaration II. All subjects signed the informed consent prior to the beginning of study. Sixty seven patients were administered with $30 \mathrm{mg}$ oral pioglitazone (Kasiping, Hangzhou, China) daily for 12 consecutive weeks. They were instructed to maintain the same levels of energy intake and physical activity throughout the entire study. We also applied for a clinical admission from Chinese Clinical Trial Registration (registration number: ChiCTR-RNC12001949).

\section{Clinical measurements}

Venous blood samples were collected from subjects in the fasting state after an overnight fasting and $2 \mathrm{~h}$ after a standardized breakfast before and after 12 weeks of administration. Concentrations of FPG, PPG, TG, TC, HDL-c, LDL-c and HbAlc were determined as previously described ${ }^{[24]}$. Body mass index (BMI) was calculated as weight in kilograms divided by body height in squared meters.

\section{Genotyping}

Genomic DNA was extracted from peripheral blood leukocytes using the Promega DNA purification kit (Promega, Madison, WI, USA) and distributed on master plates with all steps recorded by a sample tracking system. Genotyping was performed using MALDI-TOF mass spectrometry of allelespecific primer extension products generated from amplified DNA sequences (MassARRAY, SEQUENOM Inc, San Diego, CA, USA). Primers were purchased from Metabion $\mathrm{GmbH}$ (Planegg-Martinsried, Germany).

\section{Statistical analysis}

Data were presented as mean \pm SD. Statistical analyses were performed with SPSS software (Version 17.0 for Windows; SPSS Inc, Chicago, IL, USA). The genotype frequencies were compared using Pearson $\chi^{2}$ analysis. Multivariate ORs were calculated using a logistic regression analysis while adjusting for age, gender and BMI. The differences before and after pioglitazone treatment were analyzed by paired $t$-tests. To compare changes between different genotypes after pioglitazone treatment, we used explored statistical analysis to determine the distribution of our data, and performed two-sample $t$ test for normally distributed data and Mann-Whitney test for nonnormally distributed data. Statistical power was calculated with power calculator software PASS (www.ncss.com). A twosided $P$-value $<0.05$ was considered to be statistically significant.

\section{Results}

\section{Polymorphism distributions and association study}

We analyzed the distribution of PPAR- $\gamma 2$ gene rs1801282 and PTPRD gene rs17584499 polymorphisms in 197 type 2 diabetes subjects and 212 healthy controls (Table 1). Both SNPs were found to be in Hardy-Weinberg equilibrium $(P>0.05)$. We first studied the association of allelic frequencies of PPAR- $\gamma 2$ gene rs1801282 and PTPRD gene rs17584499 polymorphisms with type 2 diabetes susceptibility, and found that the allelic frequencies of PPAR- $\gamma 2$ gene rs1801282 polymorphism showed no significant differences between type 2 diabetes and con- 
Table 1. Distribution of gene polymorphisms and association results for type 2 diabetes.

\begin{tabular}{|c|c|c|c|c|c|c|c|c|c|c|}
\hline & \multicolumn{3}{|c|}{ Type 2 diabetes patients group } & \multicolumn{2}{|c|}{ Healthy control group } & ${ }^{\Delta} P$ & \multirow{2}{*}{$\begin{array}{c}\text { OR }(95 \% \mathrm{Cl}) \\
\text { (Univariate analysis) }\end{array}$} & \multirow[t]{2}{*}{${ }^{\#} P$} & \multirow{2}{*}{$\begin{array}{c}\text { OR }(95 \% \mathrm{Cl}) \\
\text { (Multivariate analysis) }\end{array}$} & \multirow[t]{2}{*}{${ }^{\dagger} P$} \\
\hline Genotype frequency & & $n$ & $\%$ & $n$ & $\%$ & & & & & \\
\hline \multicolumn{11}{|l|}{ PPAR-y2 rs1801282 } \\
\hline & $\mathrm{CC}$ & 180 & 91.37 & 180 & 84.91 & & 1 & & 1 & \\
\hline & CG & 17 & 8.63 & 32 & 15.09 & $0.044^{\mathrm{b}}$ & $0.531(0.285-0.991)$ & $0.047^{\mathrm{b}}$ & $0.515(0.268-0.990)$ & $0.047^{b}$ \\
\hline \multicolumn{11}{|l|}{ PTPRD rs17584499 } \\
\hline & $\mathrm{CC}$ & 145 & 73.60 & 179 & 84.43 & & 1 & & 1 & \\
\hline & Ст & 49 & 24.87 & 31 & 14.62 & $0.026^{b}$ & $1.945(1.194-3.169)$ & $0.008^{c}$ & $1.984(1.135-3.469)$ & $0.016^{\mathrm{b}}$ \\
\hline & TT & 3 & 1.52 & 2 & 0.94 & & & & & \\
\hline Allele frequency & & $n$ & $\%$ & $n$ & $\%$ & & & & & \\
\hline \multicolumn{11}{|l|}{ PPAR-y2 rs1801282 } \\
\hline & $\mathrm{C}$ & 377 & 95.69 & 392 & 92.45 & & & & & \\
\hline & $\mathrm{G}$ & 17 & 4.31 & 32 & 7.55 & 0.052 & $0.552(0.302-1.012)$ & 0.055 & $0.544(0.290-1.020)$ & 0.058 \\
\hline \multicolumn{11}{|l|}{ PTPRD rs17584499 } \\
\hline & $\mathrm{C}$ & 339 & 86.04 & 389 & 91.75 & & & & & \\
\hline & $\mathrm{T}$ & 55 & 13.96 & 35 & 8.25 & $0.009^{c}$ & $1.793(1.145-2.806)$ & $0.011^{\mathrm{b}}$ & $1.904(1.137-3.189)$ & $0.014^{\mathrm{b}}$ \\
\hline
\end{tabular}

${ }^{\Delta} P$ values: for comparison between type 2 diabetes patients and healthy control by $\chi^{2}$ test; ${ }^{\#} P$ values and their ORs: for comparison between genotypes by logistic regression analysis in dominant model; ${ }^{\dagger} P$ values and their ORs: for multivariate analyses after adjusted for age, gender and BMI. ${ }^{b} P<0.05$, ${ }^{\mathrm{c}} \mathrm{P}<0.01$.

trol $(P=0.052)$, and that the allelic frequencies of PTPRD gene rs17584499 polymorphism showed significant association with type 2 diabetes $(P=0.009)$. To further explore their correlation with type 2 diabetes susceptibility, we next analyzed their relationship stratified by genotypes. As a result, the PPAR- $\gamma 2$ gene rs1801282 polymorphism heterozygote CG genotypic frequency was higher in the healthy control group than that in the type 2 diabetes patients group $(15.09 \%$ vs $8.63 \%, P<0.05)$. The PPAR- $\gamma 2$ gene rs1801282 polymorphism was significantly associated with type 2 diabetes and CG genotype carriers had a relative protection of 0.515 (95\% CI 0.268-0.990, $P<0.05$ ) in a dominant model adjusted for age, gender and BMI. The PTPRD gene rs17584499 polymorphism homozygote TT genotypic frequency was higher in type 2 diabetes patients than that in healthy controls $(1.52 \%$ vs $0.94 \%, P<0.05)$. Since the genotypic frequency of TT was very low $(1.52 \%)$, we used dominant model (CC vs CT+TT) and compared CC and CT+TT in therapeutic efficacy analysis. The rs17584499 polymorphism was significantly associated with type 2 diabetes and CT+TT genotypes carriers had a relative risk of 1.984 (95\% CI 1.135-3.469, $P<0.05)$ in a dominant model adjusted for age, gender and BMI.

\section{Comparisons of baseline characteristics between type 2 diabetes} patients with different genotypes

A total of 67 type 2 diabetes patients (39 male, 28 female) were treated with $30 \mathrm{mg}$ pioglitazone daily for 3 months. Pioglitazone significantly decreased the concentrations of FPG $(P<0.001)$, PPG $(P<0.001)$, HbA1c $(P<0.001)$, total cholesterol $(P<0.01)$, triglyceride $(P<0.01)$ and LDL-c $(P<0.01)$ in type 2 diabetes patients (Table 2$)$.
Table 2. Clinical characteristics of all type 2 diabetes patients before and after pioglitazone treatment $(n=67)$.

\begin{tabular}{lrrr}
\hline Parameters & \multicolumn{1}{c}{ Before } & \multicolumn{1}{c}{ After } & $P$ values \\
\hline $\mathrm{BMI}\left(\mathrm{kg} / \mathrm{m}^{2}\right)$ & $25.15 \pm 2.77$ & $24.93 \pm 2.78$ & 0.091 \\
$\mathrm{FPG}(\mathrm{mmol} / \mathrm{L})$ & $8.34 \pm 1.20$ & $7.00 \pm 0.97$ & $<0.001^{\circ}$ \\
$\mathrm{PPG}(\mathrm{mmol} / \mathrm{L})$ & $13.15 \pm 3.24$ & $10.81 \pm 2.73$ & $<0.001^{\circ}$ \\
$\mathrm{HbA} 1 \mathrm{c}(\%)$ & $7.55 \pm 1.31$ & $6.73 \pm 0.87$ & $<0.001^{\circ}$ \\
$\mathrm{TC}(\mathrm{mmol} / \mathrm{L})$ & $5.01 \pm 0.93$ & $4.69 \pm 0.84$ & $<0.002^{\mathrm{c}}$ \\
$\mathrm{TG}(\mathrm{mmol} / \mathrm{L})$ & $2.00 \pm 1.14$ & $1.67 \pm 0.87$ & $<0.001^{\circ}$ \\
$\mathrm{HDL}-\mathrm{c}(\mathrm{mmol} / \mathrm{L})$ & $1.12 \pm 0.31$ & $1.18 \pm 0.34$ & $<0.224$ \\
LDL-c $(\mathrm{mmol} / \mathrm{L})$ & $3.04 \pm 0.82$ & $2.72 \pm 0.75$ & $<0.002^{\mathrm{c}}$ \\
\hline
\end{tabular}

BMI, body mass index; FPG, fasting plasma glucose; PPG, postprandial plasma glucose; HbA1c, glycated hemoglobin; TC, total cholesterol; TG, triglyceride; HDL-c, high-density lipoprotein cholesterol; LDL-c, lowdensity lipoprotein cholesterol. Data are given as mean \pm SD. $P$ values are determined by paired student's $t$ test. ${ }^{c} P<0.01$.

There was no significant difference in baseline levels of clinical and biochemical characteristics between patients with CC genotype and CG genotype of PPAR-ү2 rs1801282 polymorphism or between patients with CC genotype and CT+TT genotypes of PTPRD rs17584499 polymorphism (Table 3).

Influence of PPAR-y2 and PTPRD gene polymorphisms on therapeutic efficacy of pioglitazone in type 2 diabetes patients

After treatment with pioglitazone for 3 months, type 2 diabetes patients carrying rs1801282 CG genotypes showed higher FPG DV values (mmol/L) (DV -2.24 0.82 ) and TG DV 
Table 3. The baseline characteristics of all type 2 diabetes patients with various genotypes for the PPAR-y2 rs1801282 and PTPRD rs17584499 polymorphisms before the administration of pioglitazone $(n=67)$.

\begin{tabular}{|c|c|c|c|c|c|c|}
\hline \multirow{2}{*}{ Parameters } & \multicolumn{2}{|c|}{ PPAR-y2 rs1801282 } & \multicolumn{4}{|c|}{ PTPRD rs17584499 } \\
\hline & $\mathrm{CC}$ & $C G$ & $P$ & $\mathrm{CC}$ & $\mathrm{CT}+\mathrm{TT}$ & $P$ \\
\hline № (male/female) & $60(35 / 25)$ & $7(4 / 3)$ & $0.952^{\Delta}$ & $45(24 / 21)$ & $22(15 / 7)$ & $0.247^{\Delta}$ \\
\hline Age (year) & $56.77 \pm 8.34$ & $55.43 \pm 10.41$ & $0.704^{\dagger}$ & $55.62 \pm 7.98$ & $58.68 \pm 9.33$ & $0.100^{\dagger}$ \\
\hline Duration (month) & $41.67 \pm 35.22$ & $67.71 \pm 63.57$ & $0.367^{\dagger}$ & $42.16 \pm 39.34$ & $48.96 \pm 39.58$ & $0.389^{\dagger}$ \\
\hline BMI & $25.29 \pm 2.79$ & $23.91 \pm 2.39$ & $0.213^{\#}$ & $25.18 \pm 2.59$ & $25.07 \pm 3.17$ & $0.713^{\dagger}$ \\
\hline $\operatorname{HbA1c}(\%)$ & $7.49 \pm 1.26$ & $8.03 \pm 1.78$ & $0.492^{\dagger}$ & $7.65 \pm 1.29$ & $7.34 \pm 1.36$ & $0.216^{\dagger}$ \\
\hline $\mathrm{TC}(\mathrm{mmol} / \mathrm{L})$ & $4.99 \pm 0.92$ & $5.23 \pm 1.08$ & $0.608^{\dagger}$ & $5.09 \pm 0.98$ & $4.86 \pm 0.82$ & $0.530^{\dagger}$ \\
\hline $\mathrm{TG}(\mathrm{mmol} / \mathrm{L})$ & $1.96 \pm 1.14$ & $2.40 \pm 1.17$ & $0.223^{\dagger}$ & $2.06 \pm 1.22$ & $1.88 \pm 0.97$ & $0.694^{\dagger}$ \\
\hline $\mathrm{HDL}-\mathrm{c}(\mathrm{mmol} / \mathrm{L})$ & $1.10 \pm 0.32$ & $1.24 \pm 0.29$ & $0.223^{\dagger}$ & $1.13 \pm 0.36$ & $1.09 \pm 0.19$ & $0.298^{\dagger}$ \\
\hline LDL-c (mmol/L) & $3.02 \pm 0.82$ & $3.18 \pm 0.89$ & $0.697^{\dagger}$ & $3.06 \pm 0.90$ & $2.98 \pm 0.64$ & $0.841^{\dagger}$ \\
\hline
\end{tabular}

BMI, body mass index; FPG, fasting plasma glucose; PPG, postprandial plasma glucose; HbA1c, glycated hemoglobin; TC, total cholesterol; TG, triglyceride; HDL-c, high-density lipoprotein cholesterol; LDL-c, low-density lipoprotein cholesterol. ${ }^{\Delta} P$ values are determined by Pearson $X^{2}$ test. ${ }^{\#} P$ values are assessed by two-sample $t$-test. ${ }^{\dagger} P$ values are determined by Mann-Whitney test.

values $(\mathrm{mmol} / \mathrm{L})(\mathrm{DV}-0.89 \pm 0.48)$ compared with those with rs1801282 CC genotype (DV $-1.23 \pm 1.24, P<0.05 ;$ DV $-0.27 \pm 0.82$, $P<0.05$, respectively) (Table 4, Figure 1 ).

For PTPRD gene rs17584499, CT+TT genotypes carriers showed lower PPG DV levels (mmol/L) (DV -0.63 \pm 3.26 ) compared with those with CC genotype (DV $-3.18 \pm 3.37, P<0.01$ ) after treated with pioglitazone for 3 months (Table 4, Figure 2).

\section{Discussion}

In the present study, we explored the effects of PPAR- $\gamma 2$ rs1801282 and PTPRD rs17584499 polymorphisms on pioglitazone response in Chinese Han type 2 diabetes patients. Our study suggested that diabetes risk alleles in PPAR- $\gamma^{2}$ rs1801282 and PTPRD rs17584499 polymorphisms were asso-
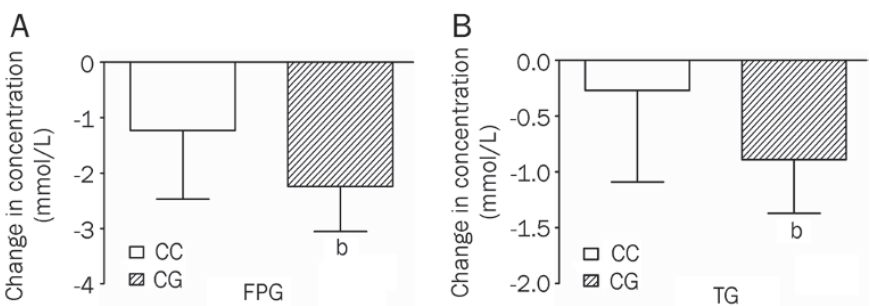

Figure 1. Comparisons of differential values (post-administration minus pre-administration) of (A) fasting plasma glucose (FPG) and (B) triglyceride (TG) between the CC genotypes and CG genotypes of the PPAR-y2 rs 1801282 polymorphism in type 2 diabetes patients after treatment with pioglitazone. ${ }^{\mathrm{b}} \mathrm{P}<0.05$.

Table 4. Comparisons of differential values (DV, post-administration minus pre-administration) in type 2 diabetes patients with different PPAR-y2 rs1801282 and PTPRD rs17584499 polymorphisms after pioglitazone treatment $(n=67)$.

\begin{tabular}{|c|c|c|c|c|c|c|}
\hline \multirow{2}{*}{ Parameters } & \multicolumn{2}{|c|}{ PPAR-y2 rs1801282 } & \multicolumn{4}{|c|}{ PTPRD rs17584499 } \\
\hline & $\mathrm{CC}$ & CG & $P$ & $\mathrm{CC}$ & $\mathrm{CT}+\mathrm{TT}$ & $P$ \\
\hline № (male/female) & $60(35 / 25)$ & $7(4 / 3)$ & $0.952^{\Delta}$ & $45(24 / 21)$ & $22(15 / 7)$ & $0.247^{\Delta}$ \\
\hline DV FPG (mmol/L) & $-1.23 \pm 1.24$ & $-2.24 \pm 0.82$ & $0.015^{\mathrm{tb}}$ & $-1.36 \pm 1.17$ & $-1.29 \pm 1.39$ & $0.830^{\#}$ \\
\hline DV PPG (mmol/L) & $-2.56 \pm 3.55$ & $-0.45 \pm 2.78$ & $0.260^{\dagger}$ & $-3.18 \pm 3.37$ & $-0.63 \pm 3.26$ & $0.005^{\# c}$ \\
\hline DV HbA1c (\%) & $-0.75 \pm 1.24$ & $-1.39 \pm 0.93$ & $0.132^{\dagger}$ & $-0.92 \pm 1.31$ & $-0.61 \pm 1.01$ & $0.303^{\dagger}$ \\
\hline DV TC (mmol/L) & $-0.36 \pm 0.79$ & $-0.10 \pm 1.06$ & $0.539^{\dagger}$ & $-0.40 \pm 0.85$ & $-0.17 \pm 0.75$ & $0.130^{\dagger}$ \\
\hline DV TG (mmol/L) & $-0.27 \pm 0.82$ & $-0.89 \pm 0.48$ & $0.010^{\text {tb }}$ & $-0.35 \pm 0.82$ & $-0.30 \pm 0.79$ & $0.530^{\dagger}$ \\
\hline DV HDL-c (mmol/L) & $-0.08 \pm 0.36$ & $-0.08 \pm 0.62$ & $0.830^{\dagger}$ & $-0.09 \pm 0.40$ & $-0.00 \pm 0.38$ & $0.857^{\dagger}$ \\
\hline DV LDL-c (mmol/L) & $-0.34 \pm 0.80$ & $-0.16 \pm 0.99$ & $0.580^{\#}$ & $-0.39 \pm 0.83$ & $-0.18 \pm 0.77$ & $0.400^{\dagger}$ \\
\hline
\end{tabular}

DV, differential value (3 months post-administration minus 0 month pre-administration); FPG, fasting plasma glucose; PPG, postprandial plasma glucose; HbA1c, glycated hemoglobin; TC, total cholesterol; TG, triglyceride; HDL-c, high-density lipoprotein cholesterol; LDL-c, low-density lipoprotein cholesterol. ${ }^{\Delta} P$ values are determined by Pearson $x^{2}$ test. ${ }^{\#} P$ values are assessed by two-sample $t$-test. ${ }^{\dagger} P$ values are determined by Mann-Whitney test. ${ }^{\mathrm{b}} P<0.05,{ }^{\mathrm{c}} P<0.01$. 


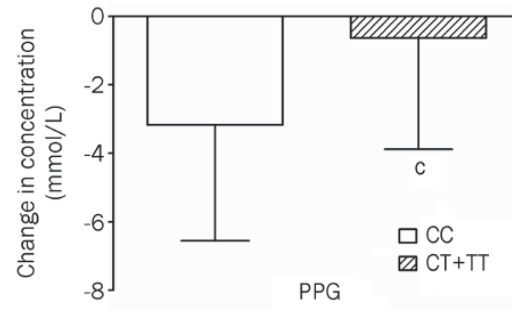

Figure 2. Comparisons of differential values (post-administration minus pre-administration) of postprandial plasma glucose (PPG) between the CC genotypes and CT+TT genotypes of the PTPRD rs17584499 polymorphism in type 2 diabetes patients after treatment with pioglitazone. ${ }^{\mathrm{C}} P<0.01$.

ciated with plasma glucose and TG after pioglitazone monotherapy in Chinese Han type 2 diabetes patients.

PPAR- $\gamma 2$ plays an important role in adipogenesis ${ }^{[25]}$ and insulin resistance. Therefore, it is one of the priority candidate genes associated with pioglitazone response and type 2 diabetes treatment. An in vitro study showed that mutated PPAR- $\gamma 2$ gene rs1801282 polymorphism reduced transcriptional activation and adipogenesis induced by a thiazolidinedione drug compared to the wild-type gene ${ }^{[26]}$. Hence, we hypothesized that the polymorphism in PPAR- $\gamma 2$ gene rs1801282 might partially account for individual differences in pioglitazone therapeutic efficacy. We first found out that the rs1801282 polymorphism was significantly associated with type 2 diabetes and CG genotype carriers had a protective role (OR: 0.515, 95\% CI 0.268-0.990, $P<0.05$ ) in a dominant model adjusted for age, gender and BMI. We further demonstrated that it significantly affected pioglitazone response with regard to the decrease of PPG and TG levels. Another study on Chinese Han population also revealed that patients with the CG+GG genotypes of the rs1801282 polymorphism were more likely to have a positive response to pioglitazone than patients with the CC genotype ${ }^{[27]}$. Namvaran et al $^{[28]}$ determined that the therapeutic response of Iranian diabetic patients with the CG genotype was better than those with the CC genotype, although the difference between groups did not reach statistical significance. Our results were in accordance with the above findings. However, Bluher et al ${ }^{[22]}$ reported a different result that the rs1801282 polymorphism did not affect pioglitazone response in a Caucasian population. We propose that the ethnic factor may be important for the function of PPAR- $\gamma 2$ gene polymorphisms in therapeutic response to pioglitazone in type 2 diabetes patients. A meta-analysis ${ }^{[30]}$ reported that $\mathrm{G}$ allele carriers had a greater protective effect against type 2 diabetes in Asians but not in Europeans or North Americans, as well as a greater protection in lower BMI individuals. The BMIs (mean \pm SD) was $25.15 \pm 2.77 \mathrm{~kg} / \mathrm{m}^{2}$ in our study, $26.43 \pm 4.6$ $\mathrm{kg} / \mathrm{m}^{2}$ in another Chinese population study ${ }^{[27]}, 27.45 \pm 4.23$ $\mathrm{kg} / \mathrm{m}^{2}$ in an Iranian population study ${ }^{[28]}$ and $31.0 \pm 3.3 \mathrm{~kg} / \mathrm{m}^{2}$ in the Caucasian population study ${ }^{[29]}$. Subjects with lower BMI and carrying $G$ allele of rs1801282 polymorphism showed better pioglitazone efficacy in Asians ${ }^{[27,28]}$ but not in the Caucasian population with a higher BMIs ${ }^{[29]}$. Therefore, the BMI difference in various ethnic groups may be one of the important ethnic factors, which influenced the effect of PPAR- $\gamma 2$ rs1801282 polymorphism on pioglitazone response.

PTPRD was associated with type 2 diabetes and involved in insulin signal pathway. The association was first reported in a Chinese Han population GWAS ${ }^{[9]}$. We confirmed this result and found that rs17584499 polymorphism was significantly associated with type 2 diabetes, and CT+TT genotypes carriers had a relative risk of $1.984(95 \%$ CI $1.135-3.469, P<0.05)$ in a dominant model adjusted for age, gender and BMI. PTPRD, which belongs to the R2A subfamily of PTPs, was assumed to act in the regulation of insulin signaling ${ }^{[9]}$. The R2A PTP subfamily also includes LAR, PTPRS and PTPRD, which are involved in neural development, cancer, and diabetes ${ }^{[11]}$. LARand PTPRS-deficient mice showed glucose homeostasis disorders and insulin sensitivity change. PTPs play an important role in cellular insulin action regulation. The similar structure in PTPs family proteins indicate that they perform similar functions in various tissues ${ }^{[31]}$. PTPRD may play an important role in type 2 diabetes pathogenesis but should be investigated in detail ${ }^{[9]}$.

This is the first study to investigate the effect of PTPRD rs17584499 polymorphism on the therapeutic efficacy of pioglitazone. CT+TT genotypes patients showed lower PPG DV levels compared with those carrying CC genotype after treated with pioglitazone for 3 months. We propose that PTPRD expressed in skeletal muscle may be one of targets for pioglitazone. Thiazolidinediones improved insulin sensitivity, dependent or independent of PPAR- $\gamma$ activation. It directly inhibited the mitochondrial fuel oxidation in rat isolated skeletal muscle ${ }^{[32]}$. It also increased glucose transport in skeletal muscle cells ${ }^{[32]}$. Furthermore, new thiazolidinedione derivative benzylidene-2,4-thiazolidinedione showed activation on PPAR- $\gamma$ and inhibition on PTP1B, another member of PTPs superfamily ${ }^{[33]}$. Rosiglitazone also inhibits PTP1B and enhances insulin activity in skeletal muscle of diabetic rats ${ }^{[34]}$. So PTPRD might be inhibited by pioglitazone. However, further investigation is needed to validate this hypothesis.

One of the limitations of this study is the relatively small sample size. Therefore, we calculated the power values of each analysis, which ranged from $75 \%$ to $98 \%$. Thus, we are confident that our result is reliable. Another limitation is the unavailability of pioglitazone plasma concentration. Since pioglitazone is mainly metabolized by CYP2C $8^{[35,36]}$, we selected patients with the CYP2C $8^{*} 1^{*} 1$ genotype to avoid any possible effects of CYP2C8 polymorphism on pioglitazone efficacy due to variations in the pharmacokinetics of pioglitazone.

In summary, diabetes risk alleles in PPAR- $\gamma 2$ (rs1801282) and PTPRD (rs17584499) are associated with pioglitazone therapeutic efficacy. These findings may be helpful for targeted treatment with pioglitazone for type 2 diabetes. However, further studies, including studies with a large sample size, more strict clinical experiment and mechanistic studies, are needed in the future. 


\section{Acknowledgements}

This work was supported by the National High-tech R\&D Program of China (863 Program) (2012AA02A517), National Natural Science Foundation of China (81173129 and 81202596), Program for Changjiang Scholars and Innovative Research Team in University (IRT0946).

\section{Author contribution}

Zhao-qian LIU, Zhao-hui MO and Hong-hao ZHOU designed the research; Qi PEI, Qiong HUANG, Min SONG and Yi ZHENG performed the research; Qiong HUANG and Guoping YANG analyzed the data; and Qi PEI, Ying-chun Zhao, Ji-ye YIN and Zhao-qian LIU wrote the paper.

\section{References}

1 Matsuda A, Kuzuya T. Relationship between obesity and concordance rate for type 2 (non-insulin-dependent) diabetes mellitus among twins. Diabetes Res Clin Pract 1994; 26: 137-43.

2 Altshuler D, Hirschhorn JN, Klannemark M, Lindgren CM, Vohl MC, Nemesh J, et al. The common PPARgamma Pro12Ala polymorphism is associated with decreased risk of type 2 diabetes. Nat Genet 2000; 26: 76-80.

3 Issemann I, Green S. Activation of a member of the steroid hormone receptor superfamily by peroxisome proliferators. Nature 1990; 347: 645-50.

4 Auwerx J. PPARgamma, the ultimate thrifty gene. Diabetologia 1999; 42: $1033-49$.

5 Deeb SS, Fajas L, Nemoto M, Pihlajamaki J, Mykkanen L, Kuusisto $\mathrm{J}$, et al. A Pro12Ala substitution in PPARgamma2 associated with decreased receptor activity, lower body mass index and improved insulin sensitivity. Nat Genet 1998; 20: 284-7.

6 Hamann A, Munzberg H, Buttron P, Busing B, Hinney A, Mayer H, et al. Missense variants in the human peroxisome proliferator-activated receptor-gamma2 gene in lean and obese subjects. Eur J Endocrinol 1999; 141: 90-2.

7 Yen CJ, Beamer BA, Negri C, Silver K, Brown KA, Yarnall DP, et al. Molecular scanning of the human peroxisome proliferator activated receptor gamma (hPPAR gamma) gene in diabetic Caucasians: identification of a Pro12Ala PPAR gamma 2 missense mutation. Biochem Biophys Res Commun 1997; 241: 270-4.

8 Kang ES, Park SY, Kim HJ, Kim CS, Ahn CW, Cha BS, et al. Effects of Pro12Ala polymorphism of peroxisome proliferator-activated receptor gamma2 gene on rosiglitazone response in type 2 diabetes. Clin Pharmacol Ther 2005; 78: 202-8.

9 Tsai FJ, Yang CF, Chen CC, Chuang LM, Lu CH, Chang CT, et al. A genome-wide association study identifies susceptibility variants for type 2 diabetes in Han Chinese. PLoS Genet 2010; 6: e1000847.

10 Tonks NK. Protein tyrosine phosphatases: from genes, to function, to disease. Nat Rev Mol Cell Biol 2006; 7: 833-46.

11 Chagnon MJ, Uetani N, Tremblay ML. Functional significance of the LAR receptor protein tyrosine phosphatase family in development and diseases. Biochem Cell Biol 2004; 82: 664-75.

12 Kawase T, Akatsuka Y, Torikai H, Morishima S, Oka A, Tsujimura A, et al. Alternative splicing due to an intronic SNP in HMSD generates a novel minor histocompatibility antigen. Blood 2007; 110: 1055-63.

13 Toscano C, Klein K, Blievernicht J, Schaeffeler E, Saussele T, Raimundo S, et al. Impaired expression of CYP2D6 in intermediate metabolizers carrying the $* 41$ allele caused by the intronic SNP 2988G $>$ A: evidence for modulation of splicing events. Pharmacogenet Genomics 2006; 16: 755-66.
14 Kang ES, Park SY, Kim HJ, Ahn CW, Nam M, Cha BS, et al. The influence of adiponectin gene polymorphism on the rosiglitazone response in patients with type 2 diabetes. Diabetes Care 2005; 28 : 1139-44.

15 Willson TM, Lambert MH, Kliewer SA. Peroxisome proliferatoractivated receptor gamma and metabolic disease. Annu Rev Biochem 2001; 70: 341-67.

16 Zimmet P. Addressing the insulin resistance syndrome: a role for the thiazolidinediones. Trends Cardiovasc Med 2002; 12: 354-62.

17 Gillies PS, Dunn CJ. Pioglitazone. Drugs 2000; 60: 333-43.

18 Miyazaki Y, Mahankali A, Matsuda M, Mahankali S, Hardies J, Cusi K, et al. Effect of pioglitazone on abdominal fat distribution and insulin sensitivity in type 2 diabetic patients. J Clin Endocrinol Metab 2002; 87: 2784-91.

19 Boyle PJ, King AB, Olansky L, Marchetti A, Lau H, Magar R, et al. Effects of pioglitazone and rosiglitazone on blood lipid levels and glycemic control in patients with type 2 diabetes mellitus: a retrospective review of randomly selected medical records. Clin Ther 2002; 24: 378-96.

20 Aronoff S, Rosenblatt S, Braithwaite S, Egan JW, Mathisen AL, Schneider RL. Pioglitazone hydrochloride monotherapy improves glycemic control in the treatment of patients with type 2 diabetes: a 6-month randomized placebo-controlled dose-response study. The Pioglitazone 001 Study Group. Diabetes Care 2000; 23: 1605-11.

21 Herz M, Johns D, Reviriego J, Grossman LD, Godin C, Duran S, et al. A randomized, double-blind, placebo-controlled, clinical trial of the effects of pioglitazone on glycemic control and dyslipidemia in oral antihyperglycemic medication-naive patients with type 2 diabetes mellitus. Clin Ther 2003; 25: 1074-95.

22 Lawrence JM, Reckless JP. Pioglitazone. Int J Clin Pract 2000; 54: 614-8.

23 Scherbaum WA, Goke B. Metabolic efficacy and safety of once-daily pioglitazone monotherapy in patients with type 2 diabetes: a doubleblind, placebo-controlled study. Horm Metab Res 2002; 34: 589-95.

24 Huang Q, Yin JY, Dai XP, Wu J, Chen X, Deng CS, et al. Association analysis of SLC30A8 rs13266634 and rs16889462 polymorphisms with type 2 diabetes mellitus and repaglinide response in Chinese patients. Eur J Clin Pharmacol 2010; 66: 1207-15.

25 Lehmann JM, Moore LB, Smith-Oliver TA, Wilkison WO, Willson TM, Kliewer SA. An antidiabetic thiazolidinedione is a high affinity ligand for peroxisome proliferator-activated receptor gamma (PPAR gamma). J Biol Chem 1995; 270: 12953-6.

26 Masugi J, Tamori Y, Mori H, Koike T, Kasuga M. Inhibitory effect of a proline-to-alanine substitution at codon 12 of peroxisome proliferator-activated receptor-gamma 2 on thiazolidinedione-induced adipogenesis. Biochem Biophys Res Commun 2000; 268: 178-82.

27 Hsieh MC, Lin KD, Tien KJ, Tu ST, Hsiao JY, Chang SJ, et al. Common polymorphisms of the peroxisome proliferator-activated receptorgamma (Pro12Ala) and peroxisome proliferator-activated receptorgamma coactivator-1 (Gly482Ser) and the response to pioglitazone in Chinese patients with type 2 diabetes mellitus. Metabolism 2010; 59: 1139-44.

28 Namvaran F, Azarpira N, Rahimi-Moghaddam P, Dabbaghmanesh MH. Polymorphism of peroxisome proliferator-activated receptor gamma (PPARgamma) Pro12Ala in the Iranian population: relation with insulin resistance and response to treatment with pioglitazone in type 2 diabetes. Eur J Pharmacol 2011; 671: 1-6.

29 Bluher M, Lubben G, Paschke R. Analysis of the relationship between the Pro12Ala variant in the PPAR-gamma2 gene and the response rate to therapy with pioglitazone in patients with type 2 diabetes. Diabetes Care 2003; 26: 825-31. 
30 Ludovico O, Pellegrini F, Di Paola R, Minenna A, Mastroianno S, Cardellini $\mathrm{M}$, et al. Heterogeneous effect of peroxisome proliferatoractivated receptor gamma2 Ala12 variant on type 2 diabetes risk. Obesity (Silver Spring) 2007; 15: 1076-81.

31 Pulido R, Serra-Pages C, Tang M, Streuli M. The LAR/PTP delta/PTP sigma subfamily of transmembrane protein-tyrosine-phosphatases: multiple human LAR, PTP delta, and PTP sigma isoforms are expressed in a tissue-specific manner and associate with the LARinteracting protein LIP.1. Proc Natl Acad Sci U S A 1995; 92: 1168690.

32 Brunmair B, Gras F, Neschen S, Roden M, Wagner L, WaldhausI W, et al. Direct thiazolidinedione action on isolated rat skeletal muscle fuel handling is independent of peroxisome proliferator-activated receptorgamma-mediated changes in gene expression. Diabetes 2001; 50 : 2309-15.
33 Bhattarai BR, Kafle B, Hwang JS, Ham SW, Lee KH, Park H, et al. Novel thiazolidinedione derivatives with anti-obesity effects: dual action as PTP1B inhibitors and PPAR-gamma activators. Bioorg Med Chem Lett 2010; 20: 6758-63.

34 Wu Y, Ouyang JP, Wu K, Wang SS, Wen CY, Xia ZY. Rosiglitazone ameliorates abnormal expression and activity of protein tyrosine phosphatase $1 \mathrm{~B}$ in the skeletal muscle of fat-fed, streptozotocintreated diabetic rats. Br J Pharmacol 2005; 146: 234-43.

35 Daily EB, Aquilante CL. Cytochrome P450 2C8 pharmacogenetics: a review of clinical studies. Pharmacogenomics 2009; 10: 1489-510.

36 Jaakkola T, Laitila J, Neuvonen PJ, Backman JT. Pioglitazone is metabolised by CYP2C8 and CYP3A4 in vitro: potential for interactions with CYP2C8 inhibitors. Basic Clin Pharmacol Toxicol 2006; 99: 4451. 